\title{
Emergencia de refugiados en el Mediterráneo: evaluación de las respuestas políticas de la Unión Europea
}

\author{
The Mediterranean Refugee Emergency: \\ Assessing the EU Policy Responses
}

\author{
Anna Triandafyllidou \\ Regina Mantanika*
}

Resumen. La migración irregular ha sido una preocupación prioritaria de la política de la Unión Europea (UE) en los últimos veinte años. Hasta ahora, importantes normativas han sido promovidas sobre la base de la indiscutible distinción entre los que solicitan asilo - personas que escapan a la persecución o al conflicto, la violencia y la inseguridad-y migrantes irregulares en busca de una vida mejor y oportunidades laborales. Sin embargo, la reciente emergencia de refugiados de 2015-2016 muestra que esa distinción se vuelve cada vez más inadecuada para controlar los flujos de población. No solamente los flujos sino también las motivaciones de la gente son una mezcla de varias cosas. La gente que sale de sus países lo hace para escapar de la guerra o de regímenes opresivos, y con la intención de construir un mejor futuro para ellos y sus hijos. La línea que separa al asilo de los flujos migratorios es cada vez más difusa, incluso en el terreno, ya que la gente viaja por las mismas rutas y usa las mismas redes de contrabando de personas para cruzar ilegalmente las fronteras externas de la UE. Los recientes y masivos flujos de migrantes irregulares y de solicitantes de asilo a través del Mediterráneo hacia Grecia e Italia han puesto a prueba el sistema europeo de migración y asilo, por lo que son necesarias nuevas medidas y enfoques a fin de manejar la emergencia. Este documento ofrece una caracterización general de lo que en los dos últimos años se ha conocido como la «crisis de los refugiados» y discute de manera crítica las respuestas políticas más relevantes de la UE. Se evalúan los innovadores enfoques políticos que han sido adoptados durante ese periodo, además se explora la necesidad de nuevos dispositivos conceptuales y políticos con el propósito de abordar el paisaje global contemporáneo de migración y asilo.

Palabras clave. asilo, refugiados, crisis, migración irregular, Unión Europea, gestión de fronteras, cuotas, Declaración conjunta UE-Turquía, Cumbre Valetta, ruta de los Balcanes.

\begin{abstract}
Irregular migration has been a primary policy concern for the UE in the last 20 years. Relevant policies have so far been predicated on a watertight distinction between asylum seekers - people fleeing persecution and/or conflict, violence and insecurity - and irregular migrants in search for better life and work opportunities. The recent refugee emergency of 2015-2016 however shows that such a distinction is becoming increasingly inadequate to govern population flows. Not only flows but motivations of people on the move are mixed: People, who flee their countries, do so to escape from war or oppressive regimes but with a view also of building a better future for themselves and their children. The line drawn between asylum and migration flows is increasingly blurred also on the ground as people travel the same routes and use the same smuggling networks to cross the UE's external borders unlawfully. The recent massive flows of irregular migrants and asylum seekers across the Mediterranean to Greece and Italy have put to the test the European migration and asylum framework requiring for new measures and new approaches in order to deal with the emergency. This paper offers an overview of what has been known as the refugee crisis; in the last two years and critically discusses the relevant policy responses at the EU level. It assesses innovative policy approaches undertaken during this period and further explores the need for both new conceptual and policy frameworks to deal with the current global migration and asylum landscape.
\end{abstract}

Keywords. asylum, refugee, crisis, irregular migration, European Union, border management, quotas, UETurkey joint statement, Valetta summit, Balkan route. 



\section{Introducción}

La migración irregular ha sido una preocupación política prioritaria para la Unión Europea (UE) en los últimos veinte años y muchas medidas normativas han sido adoptadas a fin de combatir ese fenómeno. Las acciones han incluido el desarrollo de un sistema de gestión de la frontera común y de los procedimientos de deportación, sanciones contra los empleadores que contraten migrantes indocumentados y cooperación con otros países de origen y tránsito en la perspectiva de detener a los migrantes irregulares antes de que lleguen al territorio de la UE. Hasta ahora, las medidas han sido promovidas sobre la base de la distinción indiscutible entre solicitantes de asilo - personas que escapan a la persecución, al conflicto, la violencia y la inseguridad-y migrantes irregulares en busca de una vida mejor y oportunidades laborales; no obstante, esa distinción se vuelve cada vez más inadecuada para controlar los flujos de población. Asimismo, no solamente los flujos son mixtos - incluyen tanto a solicitantes de asilo como a migrantes laborales (irregulares)—, también hoy las motivaciones lo son.

Las personas que se marchan de sus países intentan escapar de la guerra o de regímenes opresivos, además lo hacen con la idea de construir un mejor futuro para ellos y sus hijos. La línea que separa al asilo de los flujos migratorios es cada vez más difusa incluso en el terreno, pues la gente viaja por las mismas rutas y recurre a las mismas redes de contrabando de personas para cruzar de modo ilegal las fronteras externas de la UE. Una vez en territorio de la UE, los migrantes pueden adoptar diversas estrategias según sus opciones; por ejemplo, pueden optar por solicitar asilo (aún sabiendo que su solicitud no tiene fundamentos) como una forma de ganar tiempo y permanecer temporalmente de manera legal en un país, o elegir no solicitarlo (incluso si cuentan con numerosas posibilidades de que su solicitud sea aceptada) porque prefieran ir a otro país de la UE.

A pesar de que las tendencias ya descritas se hicieron evidentes desde hace una década y de que existían temores de que la crisis de Medio Oriente, y en particular la guerra en Siria, generaría más olas de refugiados y personas desplazadas, la magnitud de los flujos de población que cruzaron el Mediterráneo en el periodo 2015-2016 fue inesperada, sin precedentes. Más de un millón de personas viajaron principalmente a través del corredor Turquía- 
Grecia (cruzaron desde la costa turca hacia las islas griegas en el mar Egeo), y en segundo lugar por la ruta Libia-Italia (recorriendo Lampedusa o Sicilia), para arribar a las costas del sur de Europa, continuar más al norte y más al sur en 2015; mientras que otras 350 mil siguieron llegando durante 2016. Los dos corredores han atendido un conjunto diverso de nacionalidades: la ruta Turquía-Grecia ha sido recorrida sobre todo por sirios, afganos e iraquíes; en tanto, la ruta Libia-Italia fue transitada por eritreos, nigerianos, somalíes y otros grupos de nacionalidades subsaharianas.

Entre los desafíos fundamentales de la actual política de la UE es indispensable proveer protección a aquellos que la necesiten, reducir el riesgo de cruzar el Mediterráneo (la pérdida de vidas en el cruce de Libia a Italia es particularmente severa) y en última instancia, crear mecanismos legales para solicitantes de asilo y migrantes económicos. De manera que las políticas apropiadas requieren un enfoque amplio que incluya no solamente el control de la frontera sino la gestión del asilo y de la migración laboral. Las políticas inciden asimismo en el libre movimiento dentro del territorio de la UE y el Tratado de Schengen, ya que el flujo masivo de solicitantes de asilo o de migrantes irregulares en un país provoca considerables presiones en otros países.

Este artículo ofrece una caracterización general de los flujos de migrantes y de solicitantes de asilo hacia Europa en los últimos dos años y discute de forma crítica las respuestas más importantes en la UE. Se evalúan los enfoques políticos innovadores que han sido adoptados a lo largo de ese lapso y se explora la necesidad de nuevos dispositivos conceptuales y políticos para abordar el paisaje global contemporáneo de migración y asilo.

\section{La gente se mueve a través del Mediterráneo}

El mar Mediterráneo ha sido el área más intensamente transitada en lo que concierne a los flujos de migración irregular y solicitantes de asilo en la última década. Los flujos han seguido de modo general las direcciones sur a norte y este a oeste. Se identifican tres rutas principales: Mediterráneo occidental, de África occidental o subsahariana a través de Marruecos hasta España; central, de África oriental u occidental pasando por Libia (o Túnez) hasta Italia; y Mediterráneo oriental, desde Asia, Medio Oriente y en ocasiones también desde África oriental por Turquía hasta Grecia (véase gráfica 1). 


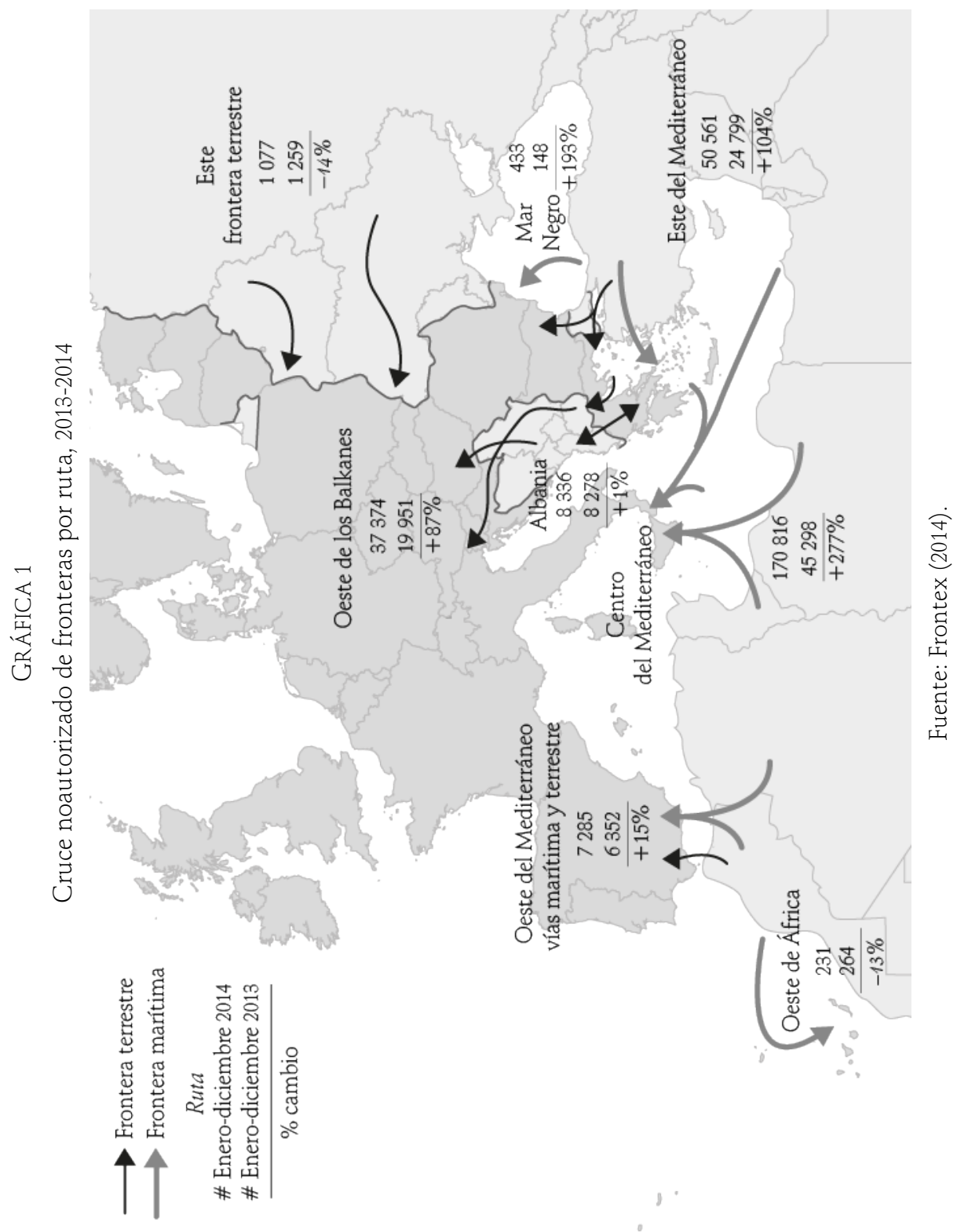


La ruta del Mediterráneo oriental ha estado bajo presión los últimos cinco años, incluso a pesar de que los flujos han cambiado constantemente durante ese periodo desde las islas (límite marítimo Grecia-Turquía) hacia tierra firme (límite terrestre Grecia-Turquía). Por ende, mientras que entre 2008 y 2009 la ruta preferida para cruzar era el mar de la costa turca a las islas egeas (Samos, Lesbos y Quíos), hubo un cambio repentino a finales de 2009: se quintuplicó el número de migrantes irregulares detenidos en la frontera terrestre Grecia-Turquía a la vez que el número de detenidos en la frontera marítima disminuyó en 70 por ciento. En 2012, la ruta se modificó de nuevo: las detenciones en la frontera terrestre disminuyeron dramáticamente, pero se triplicaron en 2013 y se cuadruplicaron en 2014 en las islas.

En 2015 se mantuvo la misma tendencia: la frontera marítima, y en particular la isla de Lesbos, concentró casi todos los cruces irregulares del país (Angeli y Triandafyllidou, 2016). De acuerdo con la Organización Internacional para la Migración (OIM), 853 mil personas llegaron a Grecia por esa ruta. La mayoría provenía de Siria, seguido en relevancia por Afganistán e Irak. Sin embargo, hubo también una pequeña proporción de personas provenientes de Palestina, Marruecos y Somalia en 2015 (gráficas 2 y 3).

\section{GRÁFICA 2}

Llegadas a través del Mediterráneo, 2015

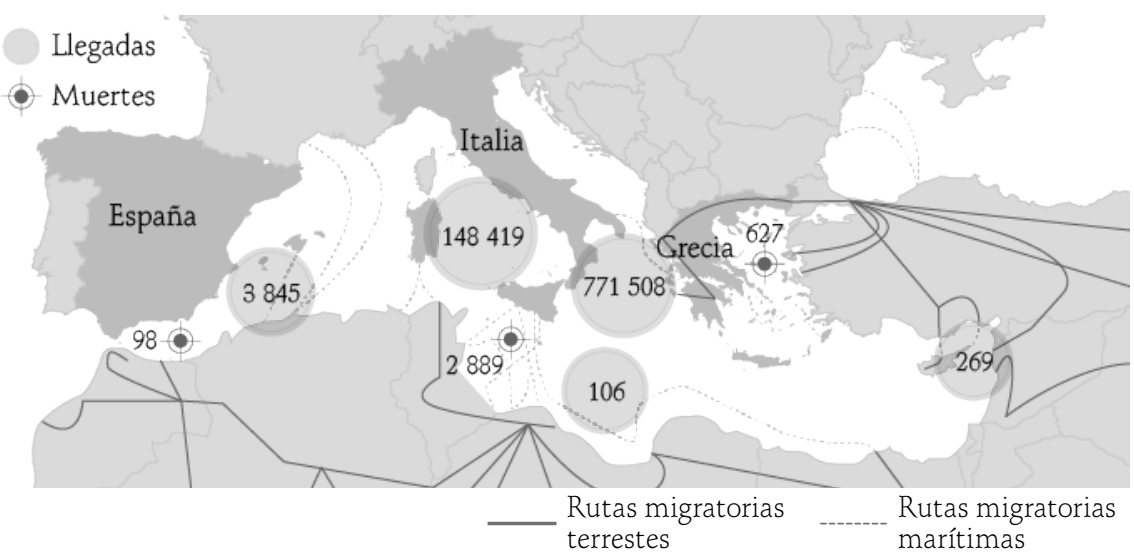

Fuente: OIM, Missing Migrants Project (2015). 


\section{GRÁFICA 3}

Llegadas a través del Mediterráneo, 2016

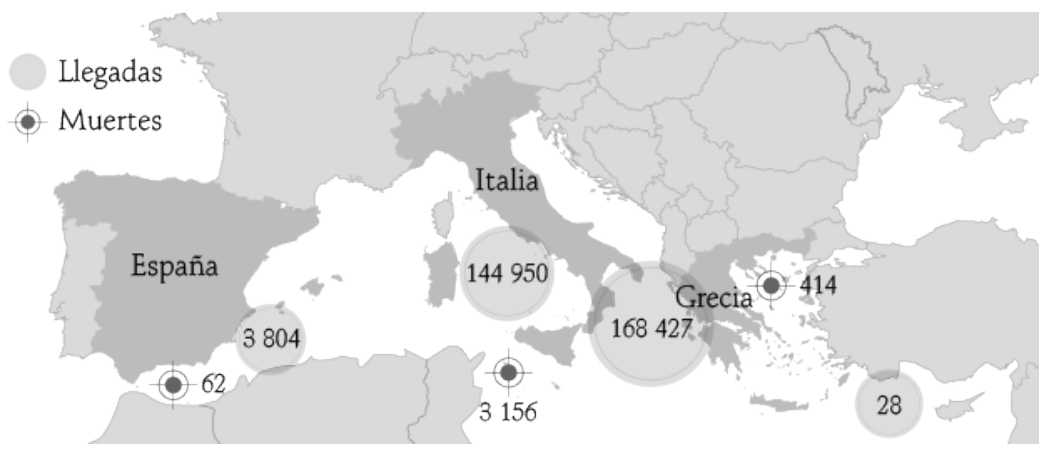

Fuente: OIM, Missing Migrants Project (2016).

La composición sociodemográfica de los flujos cambió en el periodo de auge: a principios de 2015 los niños representaban 10 por ciento de los flujos, en otoño de ese año prácticamente una de cada tres personas que llegaba a Grecia desde Turquía era menor de edad. En cuanto a las mujeres, el porcentaje permaneció constante en alrededor de 20 por ciento. Según los datos del Alto Comisionado de las Naciones Unidas para los Refugiados (ACNUR o UNHCR, por sus siglas en inglés), el número de mujeres y niños que viajaban por la ruta del Mediterráneo oriental pasó de 27 por ciento en septiembre de 2015 a 60 por ciento en marzo de 2016 (UNHCR, 2016a). Además, mientras los sirios fueron la mayoría en la primera mitad de 2015, el número de afganos se incrementó en verano, otoño e invierno de 2015, por lo que representaron una cuarta parte de los flujos.

Concerniente a la ruta del Mediterráneo central, ha registrado un elevado número de entradas irregulares a lo largo de los últimos 15 años. Italia ha reportado máximos de detenciones en su frontera marítima entre 2006y 2007; después pasó a flujos mínimos y constantes entre 2009-2010 luego de que el gobierno de Italia firmara acuerdos con el régimen de Gaddafi en Libia para hacer retornar a la gente que se embarcó en la costa de Libia hacia Italia. Las cifras se incrementaron de forma dramática a principios de 2011 y de nuevo en 2013-2014. Las llegadas se mantuvieron elevadas a lo largo de 2015, aunque hubo un relativo descenso en el número total de llegadas irregulares en comparación con el año previo (Frontex, 2016a, b, c; Europol, 2016). 


\section{GRÁFICA 4}

Principales nacionalidades que llegan a Grecia e Italia 2015-2016 (enero a agosto)
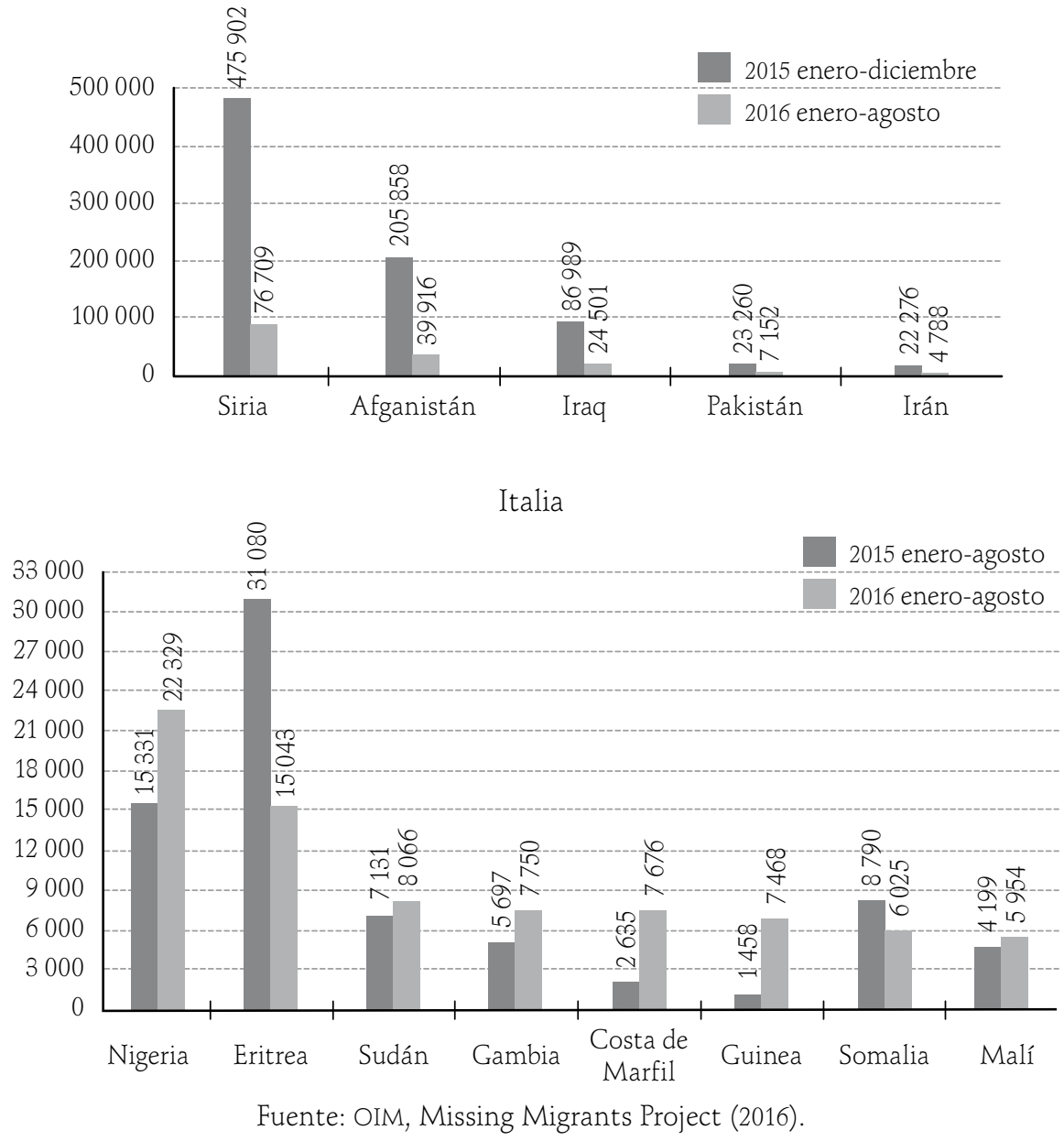

A pesar de que el número de llegadas a Italia en 2015 no es muy diferente en escala al registrado en 2014, la composición de los flujos de población migrante ha cambiado de modo notable (gráfica 4). Ha habido un claro descenso de sirios, de 24 por ciento de llegadas en 2014 a sólo 5 por ciento en 2015. Asimismo, si bien los provenientes de Eritrea componían el mayor grupo de nacionalidad única en 2015, en realidad la presencia de hombres jóvenes solteros de distintos países del África oriental y occidental subsahariana caracterizaba la ruta del Mediterráneo central en ese lapso. Dichas naciones - las más diversas entre los países de origen de 
quienes llegan a Grecia - incluyen a Eritrea, Nigeria, Somalia, Sudán, Gambia, Bangladesh, Malí y Senegal.

La ruta del Mediterráneo occidental se origina en el África subsahariana y recorre Marruecos y España, pasando por las ciudades españolas Ceuta y Melilla en el norte de África o las Islas Canarias, o a través del estrecho de Gibraltar hasta tierra firme española. Una década atrás, esta ruta fue usada principalmente por migrantes marroquíes y argelinos que buscaban mejores oportunidades laborales en Europa. A mediados de los 2000 se convirtió en la ruta preferida de los migrantes irregulares del África subsahariana que se dirigían hacia el norte motivados por conflictos regionales. Sin embargo, durante los últimos cinco años el flujo ha disminuido en importancia y en alguna medida se ha abandonado la ruta. En 2015 el número total de llegadas se redujo aún más mientras que los sirios representaban la mayoría de los cruces irregulares de frontera (Frontex, 2016d).

Grandes naufragios han caracterizado el cruce por el Mediterráneo en los últimos dos años. No es sorprendente que tales naufragios hayan sido registrados en la ruta del Mediterráneo central más que en las otras rutas. De acuerdo con el Proyecto de los Migrantes Perdidos de la OIM, en los primeros meses de 2016, uno de cada 29 migrantes murió cuando intentaba cruzar por la ruta del Mediterráneo central; en tanto que en la ruta del Mediterráneo oriental, murió uno de cada 410. Resulta claro, entonces, que el tránsito desde la costa de Libia hacia el sur de Italia es más largo y peligroso cuando se navega en botes inadecuados y sobrecargados, en contraste con el cruce desde la costa turca hasta las islas del Egeo. No obstante, el incremento del número de personas muertas y desaparecidas también se relaciona con las políticas restrictivas aplicadas en la región, en las que el control de la frontera a menudo (aunque no siempre) ha tenido prioridad sobre las obligaciones de búsqueda y rescate.

\section{La apertura de la ruta de los Balcanes}

A finales de la década de 2000 y comienzos de la de 2010, los migrantes irregulares y solicitantes de asilo provenientes de Asia o África que arribaban a la frontera sudeste de la UE, normalmente continuaban su viaje hacia los países de Europa occidental, empero, para algunos los países del sur eran el destino principal. Por ejemplo, para mucha gente de Pakistán y Bangladesh, Grecia fue el país de destino desde los 1990; por otro lado, los nigerianos tienden a quedarse 
en Italia (Kuschminder, de Bresser y Siegel, 2015; Triandafyllidou y Maroukis, 2010; Dimitriadi, 2012). Los movimientos secundarios al interior de Europa suceden según varias rutas. La ruta de los Balcanes era conocida pero no fue muy transitada hasta inicios de los 2010, ya que requería salir y volver a ingresar por las fronteras de la UE, lo que implicaba pasar por múltiples puestos de control. Sin embargo, el número de personas que viaja por la ruta de los Balcanes aumentó en 2013 por ser una alternativa al dificultoso cruce de frontera desde los puertos griegos de Patra e Igoumenitsa a Italia. Los movimientos secundarios constituían un segundo paso dentro de la UE de viajes largos que con frecuencia terminaban más al norte y al oeste en Suiza, Austria y Alemania, y algunos en Francia, Reino Unido o Suecia.

El dramático incremento en el número de llegadas de solicitantes de asilo y migrantes irregulares a las islas griegas se vincula con la activación de la ruta de los Balcanes ya descrita, la cual se convirtió en el corredor principal de los flujos de solicitantes de asilo hacia Alemania y otros países del norte de Europa (tal como Suecia) (véase gráficas 6 y 7). Aproximadamente, 900 mil migrantes viajaron por esta ruta en 2015 y otros 150 mil a principios de 2016 hasta que las fronteras fueron cerradas.Durante un periodo de varias semanas, conexiones organizadas de transporte (autobuses y trenes) facilitaron el tránsito de las personas hacia Austria y Alemania. En 2015, según Frontex (2016f), 764 mil migrantes de Siria, Afganistán e Irak, pasaron por la Antigua República Yugoslava de Macedonia (FYROM por sus siglas en inglés) y Serbia hacia Alemania y otros Estados miembros occidentales de la UE. Ello representa un incremento de 16 veces en comparación con 2014 (gráfica 5).

\section{GRÁFICA 5}

Número de cruces de frontera en las rutas occidentales de los Balcanes 2009-2015

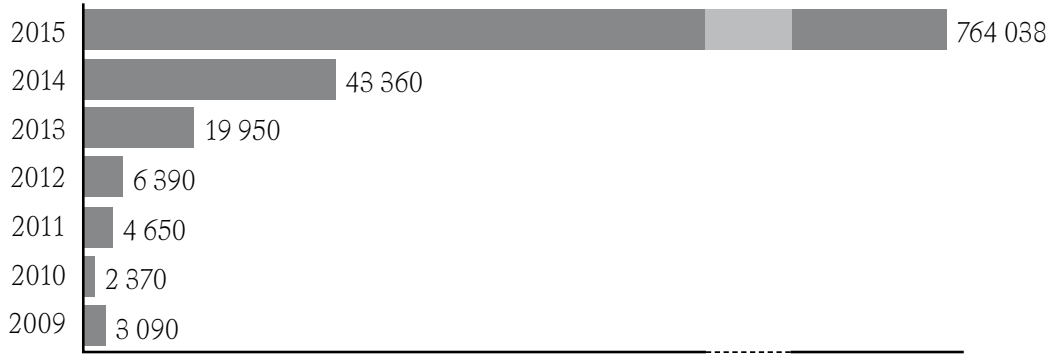

Fuente: Frontex (2016f).

${ }^{1}$ Organización conocida como la Agencia Europea de Fronteras y Guardacostas. 


\section{GRÁFICA 6}

La ruta de los Balcanes vía Hungría

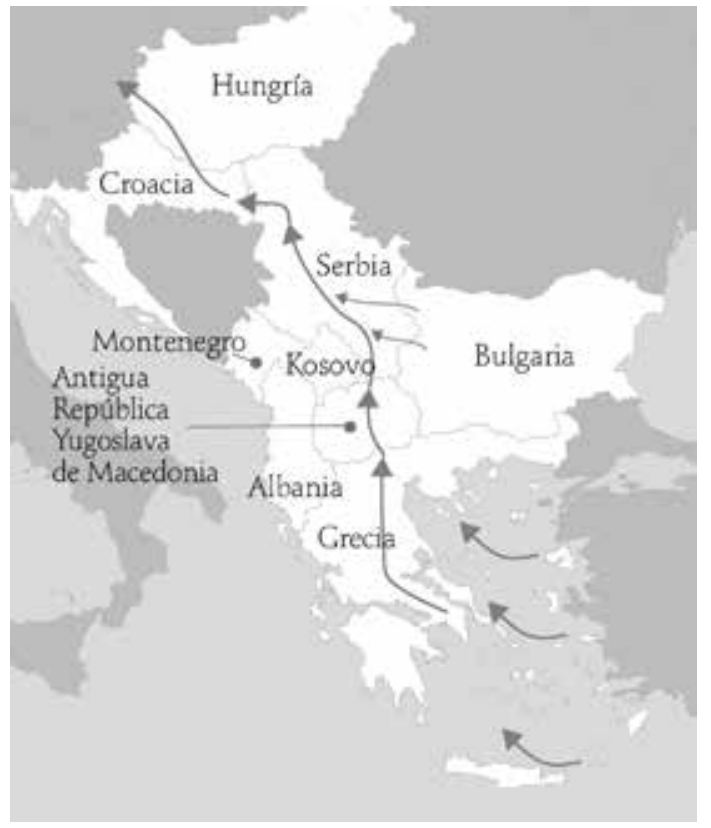

Fuente: elaboración propia.

El tremendo alcance de los flujos constituye una prueba dentro del argumento de que estaban creando un efecto de atracción para los sirios y en particular para los iraquíes, quienes por mucho tiempo fueron desplazados internamente, y los afganos, que se refugiaron en Irán, y quienes vieron en esta apertura una esperanza para un futuro mejor y más seguro. En el verano de 2015 las preocupaciones ya habían surgido en Hungría, lo que llevó al gobierno a cerrar sus fronteras con Serbia y más tarde a construir cercos en ambos lados de sus fronteras con Serbia, Austria y Croacia; luego los flujos se dirigieron a Croacia y Eslovenia. A mediados de noviembre de 2015, el tránsito por la ruta de los Balcanes se limitaba a solicitantes de asilo de Siria, Afganistán e Irak. Migrantes de otras nacionalidades fueron detenidos en la frontera de Grecia con FYROM y se los enviaba de vuelta al sur de Grecia con el propósito de procesar sus solicitudes (en el caso de solicitantes de asilo) o ser deportados (cuando se trataba de migrantes irregulares). 


\section{GRÁFICA 7}

La ruta de los Balcanes (vía Eslovenia y Croacia)

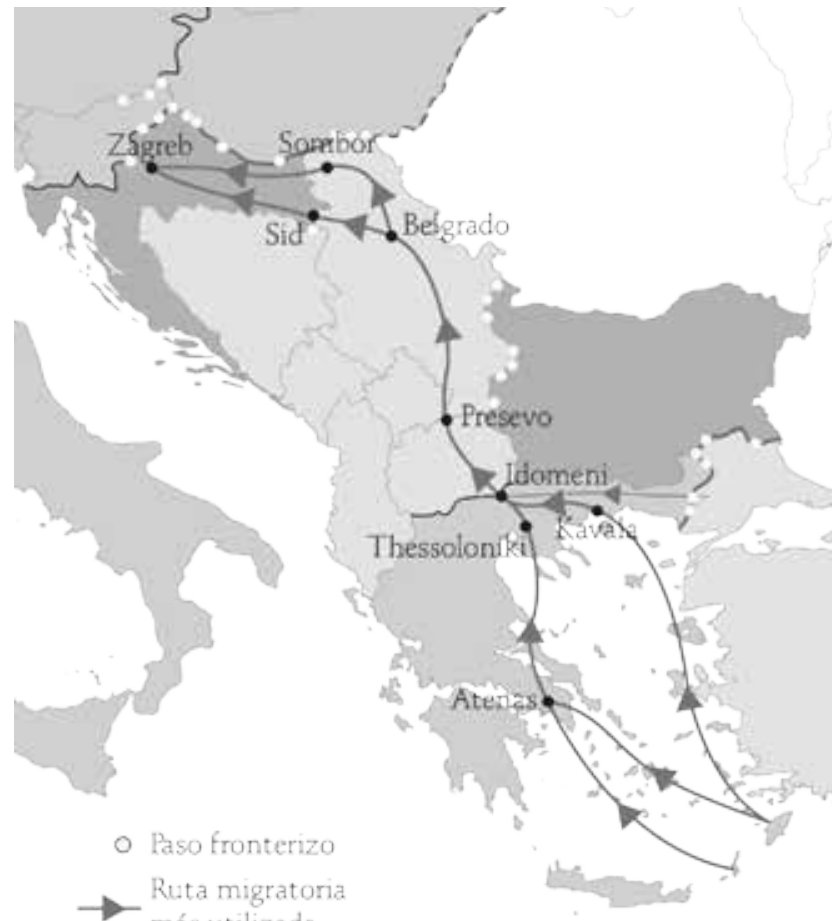

\section{Fronteras \\ Cercos \\ Cercos parcialmente planeados \\ Controles fronterizos adicionales}

Parses de la Unicin Europed

Con el Tratado

de Schengen

Sin el Tratado

de Schengen

Fuente: ACAPS (2016:4).

Debido a que a pesar de todo los flujos permanecían elevados, las autoridades policiales en los Balcanes occidentales (FYROM, Serbia) y tres Estados miembros de la UE (las repúblicas de Eslovenia, Croacia y Austria) llegaron a un acuerdo regional en la perspectiva de cerrar sus fronteras y detener el flujo de refugiados en Grecia. Además, a finales de marzo 2016, los solicitantes de asilo que llegaban fueron bloqueados en Grecia lo que propició la disminución gradual de los flujos. A partir de las preocupaciones populares acerca del número de personas ya admitidas y la posible continuidad de dicho flujo, la UE acordó en conjunto con 
Turquía, el 16 de marzo de 2016, que Turquía mantendría a la gente al interior del país y que todos los que llegaran a Europa después de esa fecha serían enviados a ese país. A cambio, a Turquía se le prometía un enorme programa de financiamiento que fomentaría la integración de cerca de 2 millones 500 mil refugiados sirios que alberga, así como facilidades de visa para sus ciudadanos.

\section{Presiones sobre el sistema de asilo de la UE}

Europa enfrenta su crisis más aguda de refugiados desde la Segunda Guerra Mundial. Ello ha significado una presión intensa sobre el Sistema Común Europeo de Asilo. Según los datos de Eurostat, Alemania recibió el mayor número de solicitudes de asilo en 2015 y tuvo el mayor incremento absoluto en aplicaciones por primera vez en comparación con 2014, seguido de Hungría, Suecia e Italia. Alemania posee la mayor proporción en el total de solicitudes de asilo de la UE: de 31 por ciento en 2014 se incrementó a 35 por ciento en 2015.

Otros Estados miembros de la UE que presentan un aumento significativo en la proporción de solicitudes de asilo son Hungría (6.6 puntos porcentuales hasta 13.9 por ciento), Austria (2.2 puntos porcentuales hasta 6.8 por ciento) y Finlandia (1.9 puntos porcentuales hasta 2.6 por ciento). Por el contrario, la participación de Francia e Italia en el total de la UE cayó casi cinco puntos porcentuales entre 2014 y 2015, a 5.6 y 6.6 por ciento respectivamente (Eurostat, 2016). Siria, Afganistán e Irak destacan como los únicos países de origen con más solicitantes de asilo, mientras que en la categoría «otro», Eritrea y Somalia, al igual que los países de los Balcanes occidentales, mantienen una sobresaliente participación.

Los datos más recientes de Eurostat referentes a 2016 confirman las tendencias de 2015. En el segundo trimestre de 2016 Alemania registró el mayor número de aplicaciones, lo que representó el mayor incremento en términos absolutos (de 101 mil 700 en comparación con el segundo trimestre de 2015). Siguen Italia y Grecia con los mayores aumentos en términos absolutos al equipararlos con el segundo trimestre de 2015 con 12 mil 200 y 9 mil 200 aplicaciones adicionales registradas, respectivamente. En cambio, en Hungría el número de solicitantes de asilo se redujo de modo significativo en $17 \mathrm{mil} 800$ (lo que corresponde a 54 por ciento), mientras que Suecia y Austria reportaron una disminución de 9 mil 800 y 6 mil 600 solicitantes de asilo (un descenso de 69 y 38 por ciento, respectivamente) en el segundo trimestre de 2016, comparado con el segundo trimestre de 2015. 


\section{GRÁFICA 8}

Solicitudes de asilo en la UE, 2014-2015

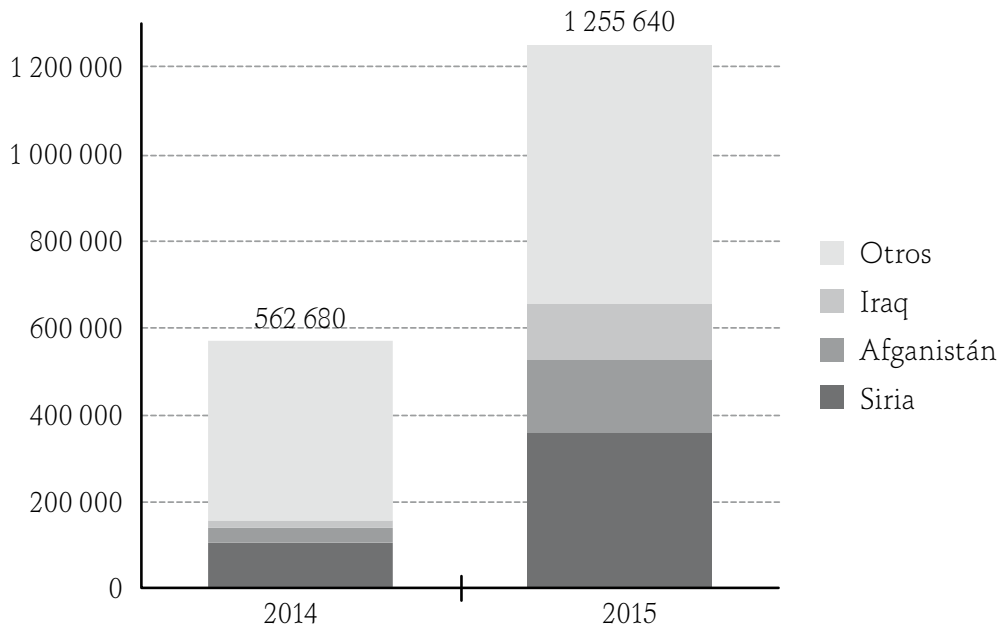

Fuente: Eurostat (2016).

Grecia notificó el segundo mayor incremento relativo de los solicitantes de asilo por primera vez, lo que equivale a tres veces más solicitudes en el segundo trimestre de 2016 en contraste con el mismo trimestre en 2015 (es decir, 9 mil 200 solicitudes adicionales). A pesar del pequeño número de solicitudes de primera vez, Croacia ha reportado el mayor incremento relativo de 13 veces (es decir, 300 solicitudes adicionales) en el segundo trimestre de 2016, comparado con el mismo trimestre de 2015.

En la UE se tomaron cerca de 600 mil decisiones acerca de solicitudes de asilo realizadas por primera vez, de las cuales 40 por ciento fue asumido por Alemania. Adicionalmente, Alemania emitió 183 mil decisiones finales (51 por ciento del total). En 2015, 52 por ciento de las decisiones sobre asilo en primera instancia en la UE tuvo un resultado positivo (estatus de refugiado o de protección subsidiaria o autorización para permanecer por razones humanitarias).

Los sirios han sido favorecidos con el mayor número de decisiones de protección por parte de los Estados miembros de la UE, lo cual incluye la protección basada en legislaciones nacionales (86 mil 400 decisiones positivas de primera instancia, es decir, una tasa de 98 por ciento de aceptación); les siguen los iraquíes (10 mil 200, 61 por ciento) y los eritreos (7 mil 600, 93 por ciento). Durante 2015, las personas menores de 35 años conformaron la mayoría de solicitantes de asilo 
por primera vez en la UE; entre ellos, el grupo de 18 y 34 años representaba 53 por ciento del total de solicitantes por primera vez y 29 por ciento de los solicitantes era menor de 18 años.

CUADRO 1

Número total de solicitudes de asilo por país, 2014-2015

\begin{tabular}{l|r:r}
\multicolumn{1}{c}{2014} & \multicolumn{1}{c}{2015} \\
\hline Alemania & 202645 & 474675 \\
Hungría & 42775 & 176325 \\
Suecia & 81180 & 160730 \\
Italia & 64625 & 76585 \\
Austria & 28035 & 67755 \\
Francia & 62735 & 57345 \\
Holanda & 26210 & 43505 \\
Bélgica & 22710 & 43010 \\
Suiza & 23555 & 33250 \\
Finlandia & 3620 & 31365 \\
Reino Unido & 31745 & 30390 \\
Noruega & 13205 & 29990 \\
Bulgaria & 11080 & 20055 \\
Dinamarca & 14680 & 17410 \\
Polonia & 8020 & 10615 \\
Grecia & 9430 & 10040 \\
España & 5615 & 9470 \\
\hline Unión Europea-28 & 626065 & 1256590 \\
\hline & $54 a t$ &
\end{tabular}

Fuente: Eurostat (2016).

\section{Respuestas políticas a la emergencia de los refugiados}

La emergencia de los refugiados desplegada en los últimos dos años (en especial desde el verano de 2015) no sólo ha afectado países en las fronteras de la UE como Grecia e Italia, sino a los países de tránsito en los Balcanes y de Europa oriental, así como a aquellos que han sido el destino final en el centro, occidente y norte de Europa. La emergencia también ha permitido apreciar que los Estados miembros de la UE son muy interdependientes y que es necesario asumir 
respuestas políticas efectivas. La siguiente sección ofrece un panorama general de tales respuestas, de su evolución e interdependencia, a la vez que intenta evaluar su impacto en los flujos, en la seguridad de los migrantes y en la gestión general de la emergencia.

Durante 2006 y 2009 las diferentes estrategias establecidas entre los Estados miembros de la UE y otros países influyeron las trayectorias de los migrantes para lograr llegar a Europa. En específico, tales estrategias procuraban interceptar a los migrantes en el mar con la intención de evadir las responsabilidades con ellos en tierra. España e Italia pusieron en práctica dichas estrategias; el primero la aplicó en la deportación de migrantes senegaleses en 2006-2007 (Gagrielli, 2008) y el segundo para deportar migrantes tunecinos en 2008 y 2011 (Cassarino, 2013). Un acuerdo firmado entre Italia y Libia en 2009, siguiendo la misma lógica, selló efectivamente la ruta del Mediterráneo central hasta el momento de los levantamientos árabes.

A lo largo de ese periodo y poco antes de los levantamientos árabes, la frontera greco-turca mostró un claro incremento en las llegadas de migrantes, lo que cambió el énfasis desde la frontera marítima a la frontera terrestre y a la inversa. Sin embargo, estas políticas de manejo y prevención de los flujos migratorios y de solicitantes de asilo por medio de la externalización de los controles han sido anuladas por una serie de eventos y factores (véase Heller y Pezzani, 2016:6-7). Entre dichos eventos se incluyen la caída de regímenes que vigilaban la entrada, en el caso de Túnez y Libia en 2011; la ilegalización de los acuerdos de contención por parte de la Corte Europea de Derechos Humanos (CEDH) en 2012 (Cuttitta, 2014); y la creciente inseguridad en muchos países de origen cuyos migrantes califican para la protección internacional al arribar a la UE.

\section{Del Mare Nostrum a la Fuerza Naval Mediterránea de la UE}

El incremento de las llegadas a través de viajes peligrosos desde Libia a Italia en 2013 y los grandes naufragios implicados al sur de Lampedusa (3 y 11 de octubre de 2013), convencieron al gobierno italiano de que se necesitaba una política diferente de gestión de la frontera marítima. La sensibilización pública y política obligó a Italia a implementar la operación Mare Nostrum, un enorme operativo de búsqueda y rescate que involucró a la marina italiana y envió barcos a buscar embarcaciones cerca a la costa Libia, los cuales rescataron más de 170 mil personas de octubre de 2013 a octubre de 2014. 
No obstante, la operación Mare Nostrum fue cuestionada por ciertos políticos de la UE quienes argumentaban que generaba un efecto de invitación para los migrantes, en tanto que el gobierno italiano se agotaba al gastar 11 millones de euros mensuales por apoyar una operación orientada a enfrentar un desafío considerado un asunto compartido por los europeos y no un problema italiano. En consecuencia, Mare Nostrum fue reemplazada por una operación orquestada por Frontex, más pequeña (en presupuesto y misión), denominada Tritón y que comenzó a ser implementada en noviembre de 2014. Por tanto, se hizo efectivo el cambio desde una amplia política humanitaria hacia una política de gestión de las fronteras marítimas más enfocada en la seguridad. De acuerdo con Heller y Pezzani (2016), la decisión resultó ser desastrosa en cuanto a los riesgos que los migrantes enfrentan en el mar, y al mismo tiempo fracasó en la reducción de las llegadas. Los datos acerca de las llegadas y las muertes en el mar en los primeros meses de 2015 corroboran este punto: en los primeros cuatro meses de 2014 se registraron 26 mil cruces y 50 decesos; en el mismo periodo en 2015, con un número casi idéntico de cruces, el número de muertes se elevó a mil 687 (Heller y Pezzani, 2016:16).

Dos trágicos naufragios adicionales, ocurridos el 12 y el 18 de abril de 2015, evidenciaron las mortales consecuencias de la era post Mare Nostrum. Esto provocó un cambio en la respuesta de la UE a finales de abril que triplicó el presupuesto y los medios para la operación Tritón, también se incrementaron los navíos de rescate no gubernamentales y se inició una campaña militar masiva para enfrentar el contrabando de migrantes. La operación FUNAMEU² se encargó de realizar «reconocimiento, monitoreo y vigilancia de los cruces ilegales en el estrecho entre Turquía y Grecia» (Garelli y Tazzioli, 2016). Asimismo, en febrero de 2016 hubo un importante cambio en el control del Mar Egeo. Turquía, Grecia y Alemania solicitaron patrullas fronterizas reforzadas con el apoyo de una flota de la Organización del Tratado del Atlántico Norte (OTAN). Por primera vez, barcos de guerra operaron tanto en aguas internacionales como en aguas territoriales con el objetivo de controlar la migración. De ese modo, la OTAN amplió su jurisdicción para controlar simultáneamente aguas internacionales y nacionales, es decir, en áreas donde las autoridades de la UE no tenían jurisdicción oficial. En opinión de Garelli y Tazzioli (2016), mientras en el Mediterráneo central tenían lugar operaciones

\footnotetext{
${ }^{2}$ Nota del traductor. La sigla corresponde a la Fuerza Naval Mediterránea de la Unión Europea, que se propone como una versión de la sigla original EUNAVFORMED correspondiente a «European Union Naval Force Mediterranean».
} 
similares, la intervención de la OTAN debe considerarse parte de un enfoque general que se presenta como una intervención humanitaria en oposición al contrabando y una operación de seguridad centrada en la migración irregular.

Los patrones de la ruta del Mediterráneo central en comparación con la ruta oriental se han desarrollado de diferentes maneras, dada la extensión y los peligros del viaje. Mientras que por un lado, las políticas de búsqueda y rescate han salvado muchas vidas, por otro, han podido tener el paradójico efecto de hacer que las redes de contrabando sean más organizadas para evadir los controles y así evitar que éstos se conviertan en intervenciones de rescate (MEDMIG Proyect, 2016).

\section{El enfoque de las zonas críticas}

Una de las primeras respuestas en 2015 fue el denominado enfoque de las zonas críticas (hotspots) establecido en Grecia e Italia, introducido por la Comisión Europea en su propuesta de Agenda Europea de Migración. El enfoque se resume como la identificación, el registro y la toma de huellas dactilares de los migrantes que llegan a través de procedimientos que se llevan a cabo en campos específicos situados en las fronteras. En Grecia existen cinco zonas críticas que operan en las islas en las que se monitorean y canalizan a los recién llegados por los procedimientos adecuados. En Italia hay cuatro zonas críticas que funcionan en el área de Sicilia y en el sur del país (Oxfam, 2016).

Una mirada más acuciosa al estado de la cuestión en las zonas críticas evidencia que en octubre de 2016 había un número significativo de expertos de Frontex y de la Agencia Europea de Apoyo a los solicitantes de Asilo, ${ }^{3}$ que trabajaban en todos los centros de Italia y una cantidad considerablemente mayor de expertos en las zonas críticas de Grecia. ${ }^{4}$ La presencia de la UE en las zonas críticas en Grecia se complementa con la asistencia de organizaciones internacionales tales como UNHCR, Médicos Sin Fronteras y el Consejo Noruego para los Refugiados. De manera similar, en Italia varias organizaciones actúan en las zonas críticas, por ejemplo UNHCR, OIM, Cruz Roja Italiana, Save the Children y Médicos Sin Fronteras, entre otros. ${ }^{5}$

\footnotetext{
${ }^{3}$ Nota del traductor. Se ha propuesto la denominación Agencia Europea de Apoyo a los solicitantes de Asilo como la traducción de EASO (European Asylum Support Office).

${ }^{4}$ A fin de tener un panorama general de la presencia de la UE en las zonas críticas y una presentación de las tareas de cada agencia, véase Comisión Europea (2016c).

${ }^{5}$ Para un análisis detallado de la situación de las zonas críticas en Italia, véase Oxfam (2016).
} 


\section{El Plan de Emergencia para la Reubicación y la práctica de la reinstalación}

En principio, el Plan de Emergencia para la Reubicación fue establecido en mayo de 2015 y más adelante se amplió en septiembre de 2015 (European Council Decision 2015/1061 del 22 de septiembre de 2015). Cabe resaltar que ha sido una importante respuesta política de la UE que buscaba promover la responsabilidad compartida respecto de los solicitantes de asilo entre los Estados miembros de una manera más equitativa al disminuir la presión sufrida por los Estados en la frontera. El plan contemplaba un total de 160 mil lugares de reubicación que serían asignados en un periodo de dos años (de septiembre de 2015 a septiembre de 2017); en particular, designaba 66 mil 400 lugares para reubicar a la gente desde Grecia y 39 mil para la de Italia. Bajo ese mecanismo, las nacionalidades elegibles para la reubicación son aquellas que ostentan una tasa de aceptación de al menos 75 por ciento ${ }^{6}$ por toda Europa. En consecuencia, entre las nacionalidades se incluían inicialmente a los sirios, ya que los iraquíes y los afganos no cumplían el criterio por dos puntos porcentuales, al igual que los eritreos hasta ahora.

Ha sido difícil implementar este esquema pues muchos de los Estados miembros receptores fueron reticentes en aceptar a los refugiados reubicados, lo que creó numerosas demoras administrativas. Recientemente, la Comisión Europea estableció que los Estados miembros receptores deben explicar los fundamentos por los cuales rechazan la solicitud de reubicación (Comisión Europea, 2016i). No obstante, no existen medios legales que obliguen a un Estado miembro a justificar tales decisiones negativas porque es su derecho soberano (AIRE y ECRE, 2016). Amnistía Internacional (26 de septiembre de 2016) considera que el número de personas que serán reubicadas es insuficiente frente a la actual emergencia y que la mayoría de los países ha aceptado menos de 5 por ciento del total que prometieron acomodar, mientras que otros países no han recibido a ningún refugiado.

El esquema de reubicación inició en agosto y septiembre de 2016, principalmente desde Grecia con un pronunciado incremento en la población reubicada desde este país. No obstante, el número total de reubicaciones permanece bajo

\footnotetext{
${ }^{6}$ Es importante tener en cuenta que la tasa depende de estadísticas y promedios trimestrales, y cada vez algunas nacionalidades se hallan en riesgo de ser excluidas de la reubicación (Eurostat, 2016).
} 
(para el 19 de octubre de 2016, mil 391 de Italia y 4 mil 846 de Grecia, en tanto que Grecia ha presentado cerca de 10 mil solicitudes).

\section{CUADRO 2}

El apoyo de los Estados miembros al plan de emergencia para la reubicación

(para el 19 de octubre de 2016)

Funcionarios

de enlace

nombrados

Reubicación

\begin{tabular}{|c|c|c|c|c|c|c|c|}
\hline $\begin{array}{l}\text { Estados } \\
\text { miembros }\end{array}$ & $\begin{array}{c}\text { Nombres } \\
\text { de puntos } \\
\text { de contacto } \\
\text { nacionales }\end{array}$ & Italia & Grecia & $\begin{array}{c}\text { Lugares } \\
\text { disponibles }\end{array}$ & $\begin{array}{l}\text { Reubicados } \\
\text { desde Italia }\end{array}$ & $\begin{array}{l}\text { Reubicados } \\
\text { desde Grecia }\end{array}$ & $\begin{array}{l}\text { Lugares } \\
\text { restantes } \\
\text { de los } \\
160000\end{array}$ \\
\hline Austria & & & $\mathrm{x}$ & $\mathrm{x}$ & $\mathrm{x}$ & $\mathrm{x}$ & 1953 \\
\hline Bélgica & & & & 530 & 29 & 153 & 3640 \\
\hline Bulgaria & & & & 1302 & $\mathrm{x}$ & 21 & 1281 \\
\hline Croacia & & $\mathrm{x}$ & $\mathrm{x}$ & 26 & 9 & 10 & 949 \\
\hline Chipre & & & & 80 & 10 & 42 & 268 \\
\hline $\begin{array}{l}\text { República } \\
\text { Checa }\end{array}$ & & $\mathrm{x}$ & $\mathrm{x}$ & 50 & $\mathrm{x}$ & 12 & 2679 \\
\hline Dinamarca & $\mathrm{N} / \mathrm{A}$ & N/A & $\mathrm{N} / \mathrm{A}$ & $\mathrm{x}$ & $x$ & $x$ & N/A \\
\hline Estonia & & & & 157 & $\mathrm{x}$ & 57 & 272 \\
\hline Finlandia & & & & 1120 & 322 & 430 & 1326 \\
\hline Francia & & & & 3320 & 231 & 1756 & 16827 \\
\hline Alemania & & & & 2250 & 20 & 196 & 27320 \\
\hline Grecia & & N/A & $\mathrm{N} / \mathrm{A}$ & $\mathrm{x}$ & $\mathrm{x}$ & $\mathrm{x}$ & N/A \\
\hline Hungría & & $\mathrm{x}$ & $\mathrm{x}$ & $\mathrm{x}$ & $\mathrm{x}$ & $\mathrm{x}$ & 1294 \\
\hline Irlanda & & & & 353 & $\mathrm{x}$ & 69 & 531 \\
\hline Italia & & N/A & N/A & $\mathrm{x}$ & $\mathrm{x}$ & $\mathrm{x}$ & N/A \\
\hline Letonia & & & $x$ & 491 & 8 & 95 & 378 \\
\hline Lituania & & & & 500 & $\mathrm{x}$ & 147 & 524 \\
\hline Luxemburgo & & & & 200 & 40 & 104 & 413 \\
\hline Malta & & & $\mathrm{x}$ & 131 & 46 & 24 & 61 \\
\hline Holanda & & & & 1225 & 226 & 629 & 5092 \\
\hline Polonia & & & & 100 & $\mathrm{x}$ & $\mathrm{x}$ & 6182 \\
\hline Portugal & & & & 1642 & 183 & 410 & 2358 \\
\hline Rumania & & & & 1502 & 43 & 284 & 3853 \\
\hline Eslovaquia & & & & 100 & $\mathrm{x}$ & 3 & 899 \\
\hline
\end{tabular}


Funcionarios

de enlace

nombrados

\begin{tabular}{|c|c|c|c|c|c|c|c|}
\hline $\begin{array}{l}\text { Estados } \\
\text { miembros }\end{array}$ & $\begin{array}{c}\text { Nombres } \\
\text { de puntos } \\
\text { de contacto } \\
\text { nacionales }\end{array}$ & Italia & Grecia & $\begin{array}{c}\text { Lugares } \\
\text { disponibles }\end{array}$ & $\begin{array}{l}\text { Reubicados } \\
\text { desde Italia }\end{array}$ & $\begin{array}{l}\text { Reubicados } \\
\text { desde Grecia }\end{array}$ & $\begin{array}{c}\text { Lugares } \\
\text { restantes } \\
\text { de los } \\
160000\end{array}$ \\
\hline Eslovenia & & & & 130 & 23 & 60 & 484 \\
\hline España & & & & 400 & 50 & 344 & 8927 \\
\hline Suecia & & & $\mathrm{x}$ & 300 & 39 & $\mathrm{x}$ & 3727 \\
\hline $\begin{array}{l}\text { Reino } \\
\text { Unido }\end{array}$ & N/A & N/A & N/A & N/A & $\mathrm{x}$ & $\mathrm{x}$ & $\mathrm{N} / \mathrm{A}$ \\
\hline Noruega & & & & 170 & $\mathrm{x}$ & $\mathrm{x}$ & $t b c$ \\
\hline Suiza & & & & 490 & 112 & $\mathrm{x}$ & tbc \\
\hline Liechtenstein & $\mathrm{x}$ & $\mathrm{x}$ & $\mathrm{x}$ & 43 & $\mathrm{x}$ & $\mathrm{x}$ & tbc \\
\hline Islandia & $\mathrm{x}$ & $\mathrm{x}$ & $x$ & $\mathrm{x}$ & $\mathrm{x}$ & $\mathrm{x}$ & tbc \\
\hline Total & $\begin{array}{c}\text { Todos los } \\
\text { países } \\
\text { miembros } \\
\text { de la Unión } \\
\text { Europea } \\
\text { hasta ahora } \\
\text { notificados }\end{array}$ & 23 & 19 & $\begin{array}{c}16612 \\
\text { De } 160000 \\
25 \text { países }\end{array}$ & $\begin{array}{c}1391 \\
\text { (Fuera } \\
\text { de } 39600 \text { ) }\end{array}$ & $\begin{array}{c}4846 \\
\text { (Fuera } \\
\text { de } 66400)\end{array}$ & $\begin{array}{c}92182 \\
\text { (De } 98255 \\
\text { iniciales)* }\end{array}$ \\
\hline
\end{tabular}

Reubicación

* De las 40 mil decisiones, 7 mil 745 todavía deben ser asignadas.

De las 120 mil decisiones, 54 mil todavía deben ser asignadas.

Fuente: Comisión Europea (2016i).

El esquema que acompaña a la reubicación es la reinstalación. De acuerdo con la Comisión Europea, la reinstalación es la transferencia de una persona con una nacionalidad no-europea o apátrida que ha sido identificada como necesitada de protección internacional hacia un Estado de la UE donde será admitido ya sea por razones humanitarias o con el estatus de refugiado (Comisión Europea, 2016e). Según los reportes de la Comisión Europea, los Estados miembros han seguido incrementando sus esfuerzos para la reinstalación y hasta el momento han ofrecido alternativas legales y seguras a 10 mil 695 personas de las 22 mil 504 aceptadas bajo el esquema de julio de 2015. Adicionalmente, mil 71 refugiados sirios de Turquía han sido reinstalados entre junio y septiembre, triplicando el número de personas reinstaladas, lo que entraña a mil 614 personas atendidas bajo el acuerdo entre la UE y Turquía (Comisión Europea, 2016b). 
Cooperación con otros países y la europeización

de la gestión de las fronteras y el asilo

En la medida en que los flujos crecieron y pese a la cálida bienvenida inicial de los ciudadanos europeos en los países de vanguardia y en los de destino (véase también Triandafyllidou, 2014; Triandafyllidou, 2017), se hizo evidente que era necesario una mayor cooperación con los países de origen y de tránsito, la misma que se orientaría a reducir los flujos. Esa política externa dentro de la UE ya había sido inaugurada por Federica Mogherini en la Cumbre Mediterránea Barcelona ${ }^{7}$ de noviembre de 2014. Entre el 11 y el 12 de noviembre de 2015, la Cumbre Valetta reunió a los representantes de Estado y gobierno europeos y africanos a fin de aprobar un plan de acción para «mejorar la cooperación respecto del retorno, la readmisión y la reintegración». La Cumbre Valetta fue en realidad el primero de varios pasos que involucraban países de origen y tránsito.

El elemento clave que redujo dramáticamente el número de solicitantes de asilo y los flujos de migración irregular hasta la mínima expresión fue el acuerdo firmado entre la UE y Turquía el 18 de marzo de 2015. Tal como AIRE y ECRE observan: tras el cierre de la ruta de salida de Grecia en febrero de 2016, el estrecho vínculo de la UE con Turquía pronto condujo a una resolución que buscaba cerrar la ruta a Grecia (AIRE y ECRE, 2016:9). El acuerdo establece que todos los migrantes que lleguen a las islas griegas a través de Turquía o que sean interceptados en el Mar Egeo serán devueltos a Turquía, mientras que un selecto grupo de refugiados sirios (cuyo número es igual al de los migrantes retornados a Turquía desde Grecia) serían reubicados en Europa.

Hasta el momento (24 de octubre de 2016), mil 139 personas han sido devueltas siguiendo el acuerdo bilateral de readmisión entre Grecia y Turquía (que ha existido desde 2002), otras 687 personas a causa del acuerdo UE-Turquía y 51 por el acuerdo de readmisión UE-Turquía. Sin embargo, los retornos tienen un ritmo lento para procesar las solicitudes de asilo en primera instancia por parte del Servicio Griego de Asilo (incluso con la ayuda de la Oficina Europea de Apoyo al Asilo) y también es lento el ritmo de procesamiento de apelaciones a cargo de la recien establecida Autoridad Griega de Apelaciones. ${ }^{8}$

${ }^{7}$ Nota del traductor. La denominación original es Barcelona Mediterranean Summit.

${ }^{8}$ Para conocer más al respecto, véase una evaluación crítica de la implementación del acuerdo UETurquía en ESI (2016). 
Si bien, por un lado, el acuerdo UE-Turquía da continuidad al acuerdo de readmisión firmado en diciembre de 2016 y al acuerdo de readmisión entre Grecia y Turquía firmado en 2002 y renovado en 2010; por otro lado, ese acuerdo marca un nuevo nivel de involucramiento de la UE con países de tránsito y origen. Su apego al orden legal de la UE ${ }^{9} \mathrm{y}$ su respeto hacia los derechos fundamentales y al principio de no-rechazo ha sido cuestionado por expertos legales y por organizaciones de la sociedad civil. ${ }^{10}$

Las negociaciones entre la UE y Turquía durante el otoño de 2015 y la primavera de 2016 derivaron en la firma de la declaración conjunta que ha sido complementada con un fondo de tres billones de euros, que serán desembolsados por la UE a Turquía con el propósito de financiar la provisión de servicios para la integración de los refugiados sirios en el país. Hasta octubre de 2016, ya han sido comprometidos 2 mil 239 billones de euros de un total de 3 billones de euros previstos para 2016-2017. Los beneficiarios han sido organizaciones de la sociedad civil que trabajan en Turquía.

La adopción de la declaración UE-Turquía requirió de una reforma de la Ley de Asilo griega para que la declaración conjunta pudiera ser implementada. La Ley 4375/2016 introdujo, por tanto, un régimen excepcional aplicable a las fronteras de país cuando se enfrenta a un número de llegadas particularmente grande que presenta solicitudes de asilo en la frontera. La nueva ley permite a las autoridades policiales y soldados desarmados llevar a cabo el registro de las solicitudes de asilo y establece también una versión expedita del procedimiento de frontera de no más de 14 días en primera y segunda instancia. Siguiendo con la lógica de establecer una cooperación más cercana y efectiva con países de tránsito y origen - cueste lo que cueste - se ha realizado de modo reciente la conferencia UE-Afganistán en septiembre de 2016, la cual derivó en un convenio que facilita el retorno de migrantes irregulares al país. ${ }^{11}$

Finalmente, la nueva Agencia Europea de Fronteras y Guardacostas comenzó a funcionar en octubre de 2016, instancia que refuerza e incrementa el papel de Frontex en el mar Egeo, al aumentar su monitoreo y coordinar responsabilidades de intervención en situaciones de emergencia. ${ }^{12}$ El impacto combinado de las zonas críticas, del patrullaje de la FUNAMEU y de las fuerzas de la nueva

\footnotetext{
${ }^{9}$ Véase Heijer \& Spijkerboer (2016).

${ }^{10}$ Acerca de la paradoja del acuerdo UE-Turquía, véase Collett (2016).

${ }^{11}$ Para conocer más al respecto, véase Rasmussen (2016) y Comisión Europea (2016k).

${ }^{12}$ Acerca de las responsabilidades de Frontex, véase Comisión Europea (2016g).
} 
Agencia Europea de Fronteras y Guardacostas marca un enorme cambio hacia la europeización de la gestión de las fronteras y la ampliación de la jurisdicción de la UE en este ámbito, junto con la estrecha cooperación (forzada de alguna manera), con los países de tránsito y de origen.

\section{Evaluación de las respuestas políticas de la UE a la emergencia de los refugiados y reflexiones para el futuro}

Este artículo ha revisado la emergencia de los refugiados en los últimos dos años y ha analizado las respuestas desarrolladas por la UE a nivel nacional para enfrentarla. Los flujos de solicitantes de asilo y de migrantes irregulares que llegaron a Europa a través de las rutas central y oriental del Mediterráneo no han tenido precedentes y así también lo fueron las intervenciones políticas. Se tomaron varias medidas nuevas y muy drásticas dentro de la UE y en el país. Tales medidas se realizaron bajo presión para enfrentar la emergencia y se transformaron en los ejes principales del desarrollo de la política a futuro para la gestión de las solicitudes de asilo y en general de la migración (irregular). A continuación, se mencionan los diez avances más importantes en el ámbito, los cuales moldearán la política y la praxis en el futuro.

Primero, se ha probado la inadecuación de la regulación de Dublin y del principio del primer país seguro; no obstante, por el momento es muy prematuro pensar en el reemplazo o en el cambio radical de ese principio. Empero, ahora la responsabilidad con los solicitantes de asilo es compartida entre los Estados miembros, no a partir de la llegada por medio del principio del primer país seguro sino por los mecanismos de registro, reubicación (y reinstalación). La Comisión Europea ha establecido cuotas de reubicación con el fin de aliviar las presiones en los países de primera línea (y también en los países que son los destinos primordiales). Aunque tales soluciones fueron presentadas para la emergencia, es muy probable que se transformen en mecanismos permanentes y de más largo plazo. Los criterios esenciales (tamaño del país, PIB y número de refugiados ya existentes) han sido determinados.

Segundo, si bien la cooperación con países de tránsito y de origen ha constituido un tema fundamental por al menos diez años, ahora, y seguramente desde que se introdujo la Agenda Europea sobre Migración y Movilidad en 2011, ello se ha convertido en máxima prioridad. Aunque la idea en un inicio es correcta 
(establecer el diálogo y profundizar la cooperación), la manera en que se implementa es incierta en la medida en que se convierte en el eje principal sobre el cual la UE negocia todos los demás asuntos (comercio, ayuda para el desarrollo, geopolítica). El énfasis en mejorar la cooperación con el África del norte y subsahariana y con países de origen asiático se ha inspirado en la iniciativa de la declaración conjunta UE-Turquía. Así, se tiende a pasar por alto muchos problemas: la migración no puede ser el único factor que guíe la política externa de la UE. El priorizar el problema de la migración implica sacrificar otras prioridades políticas (la protección de los derechos humanos de los solicitantes de asilo y de los migrantes irregulares) y geopolíticas. En adición, los países de tránsito y de origen podrían no ser capaces de realizar lo que se les pide, ya que su capacidad de gobernar sus ciudadanos puede ser relativamente débil. Por último, y quizá lo más importante, tal política hace recaer el peso de las solicitudes de asilo (y del manejo de la migración irregular) en los estados más débiles y pobres.

En la misma lógica se podrían crear regímenes fronterizos excepcionales en las fronteras externas de la UE cuando se verifique un flujo masivo de solicitantes de asilo o de migrantes irregulares. Tales regímenes dependen de los procedimientos de solicitud de asilo y en cierta proporción van de la mano con la cooperación entre países de origen y otros.

Tercero, existe gran preocupación para prevenir la pérdida de vidas humanas y combatir redes criminales que se aprovechan de la desesperanza de la gente. Las políticas orientadas a prevenir las pérdidas han sido temporales y parcialmente contradictorias. Con todo, la sensibilidad del público respecto de la trágica situación de numerosos solicitantes de asilo y migrantes ha crecido, lo que constituye un avance positivo. De hecho, hemos sido testigos del surgimiento, desde las bases, de un movimiento transnacional de solidaridad civil que ha actuado en Grecia, en Italia y en países de tránsito y de destino final. El movimiento ha sido espontáneo y sobre la marcha se ha beneficiado de una sustancial ayuda estatal e internacional en la medida en que los actores de la sociedad civil desempeñan un papel importante en el manejo de la emergencia. Al principio, la función de estos actores de la sociedad civil era más relevante en la búsqueda y el rescate. Antes de la disminución de los flujos sus acciones tuvieron gran trascendencia en la recepción, el acomodo y la integración a largo plazo.

Cuarto, en los ámbitos institucional y legal los avances han sido muy drásticos, muestra de ello es el establecimiento de la Agencia Europea de Fronteras y Guardacostas, lo que podría considerarse como un aspecto positivo que denota 
interdependencia y solidaridad para enfrentar fenómenos globales como la demanda de asilo y la migración. Al mismo tiempo, es posible observar que las iniciativas se refieren sobre todo a la gestión de las fronteras mientras que la gestión de la demanda de asilo sigue siendo en gran medida una cuestión nacional. La Oficina Europea de Apoyo a los solicitantes de Asilo (OEAA) todavía es una agencia pequeña y en especial marginal en el contexto político e institucional de la UE.

A la luz de dichas iniciativas políticas y del esfuerzo por gestionar de modo óptimo la demanda de asilo y los flujos de migración irregular, el contener los flujos surge como la primordial preocupación junto con la idea de que la migración (y la demanda de asilo) tal vez podrían ocurrir de una manera ordenada. En el contexto del nuevo panorama de intensos flujos de migración y de solicitantes de asilo hacia Europa persisten varios asuntos que requieren una apropiada comprensión.

Se ha resaltado la función de las redes criminales organizadas y en particular el lucrativo negocio del contrabando migrante y del tráfico de personas como factores relevantes que facilitan el movimiento inseguro e ilegal. Aun así, los actuales enfoques son dominados por una lógica de seguridad incapaz de distinguir las formas en las que las redes de contrabando integran las comunidades de origen y tránsito. El estudio más detenido acerca de cómo el contrabando de personas o de migrantes se interconecta con las dinámicas sociales y económicas locales permitirá encontrar respuestas más efectivas en el país y en la UE. Además, el contrabando de personas es una de las áreas en las que es indispensable realizar más investigaciones y emprender mayores acciones para aumentar la seguridad. Más todavía, necesitamos enfoques más innovadores en la demanda de asilo con la perspectiva de que sea posible acceder a la protección internacional en condiciones seguras.

Es pertinente resaltar que hoy somos testigos de nuevas formas de agencias de migrantes que se apoyan en la tecnología de la información. En efecto, la capacidad de un migrante o solicitante de asilo y de sus familias para planificar y llevar a cabo su viaje en la era de los teléfonos inteligentes ha crecido exponencialmente. Los individuos por sí mismos se han convertido en los actores principales de sus proyectos de migración o asilo. Pueden obtener e intercambiar información en tiempo real con otros múltiples actores, negociar opciones, navegar entre obstáculos (fronteras cerradas, políticas restrictivas, cruces peligrosos) y aprovechar oportunidades (medios de transporte, prácticas informales flexibles) de modos muy diversos. En tanto este fenómeno ha «eclosionado» 
durante la emergencia de los refugiados en los últimos dos años, es preciso investigar mejor sus dinámicas y cómo configura los flujos de migración irregular o de búsqueda de asilo. ¿̇Acaso simplemente facilita la movilidad? ¿A Aumenta o disminuye los flujos? ¿Crea nueva demanda para la migración cuando surge una oportunidad o simplemente responde a estímulos preexistentes? ¿̇Acaso les resta poder a los contrabandistas y al gobierno?

Por último, pero no por ello menos interesante, un asunto vital continúa siendo la cuestión de las motivaciones mixtas. La emergencia de los refugiados ha dejado en claro que las distinciones rígidas y rápidas entre solicitantes de asilo y migrantes laborales son difíciles de aplicar en la realidad, dado que las personas tienen motivaciones políticas y económicas cuando inician la migración. Lo que varía es la importancia relativa de cada conjunto de factores y determinantes y sus márgenes de agencia entre el desplazamiento voluntario y forzado. Nuestra propuesta es que la noción de migración forzada versus voluntaria entendida como un continuo y que incluye factores políticos, económicos o sociales como determinantes de la migración podría ofrecer un enfoque conceptual y de política más prometedor para comprender las dinámicas de los flujos internacionales de población y desarrollar respuestas de política apropiadas.

\section{Referencias}

ACAPS (2016), «Refugee/Migrant crisis in Europe: Scenarios, possible developments in transit countries over the next six months», en http://reliefweb.int/sites/reliefweb. int/files/resources/160324_greece-analysis-report.pdf

AIRE \& ECRE (2016), "With Greece. Recommendations for refugee protection», en http://www.asylumineurope.org/sites/default/files/resources/with_greece.pdf

Amnesty International (2016), «Greece: Refugees detained in dire conditions amid rush to implement EU-Turkey deal», en https://www.amnesty.org/en/latest/news/ 2016/04/greece-refugees-detained-in-dire-conditions-amid-rush-to-implement-eu -turkey-deal/

Beloni, Milena (2015), Cosmologies of Destination (unpublished PhD Thesis), Italia, University of Trento.

Bitoulas, Alexandros (2015), "Population and social conditions. Eurostat data in focus», en http://ec.europa.eu/eurostat/documents/4168041/6742650/KS-QA-15-003-ENN.pdf/b7786ec9-1ad6-4720-8a1d-430fcfc55018 
Bovens, Lucy Bartsch, Anna (2015), «Why the refugee quota system is unfair to poorer eastern and southern EU states», en http://bit.ly/1j2X97L

Collett, Elizabeth (2016), "The paradox of the EU-Turkey refugee deal», en http:// www.migrationpolicy.org/news/paradox-eu-turkey-refugee-deal

Cuttita, Paolo (2014), «From the Cap Anamur to Mare Nostrum: Humanitarianism and Migration controls at the EU's maritime borders», en Matera, Claudio y Taylor, Amanda, The Common European Asylum System and Human Rights: Enhancing Protection in Times of Emergencies, Centre for the Law of EU External Relations, Den Haag, Asser Institute.

Den Heijern, Maarten \& Spijkerboer, Thomas (2016), "Is the EU-Turkey refugee and migration deal a treaty?», en http://eulawanalysis.blogspot.gr/2016/04/is-euturkey-refugee-and-migration-deal.html

Dimitriadi, Angeliki, (2013), Transit and immigration to Greece. The case of Afghans, Pakistanis and Bangladeshis, Athens, Nisos.

ESI (2016), «How (not) to implement the Aegean Agreement» en http://www.esiweb. org/pdf/ESI\%20-\%20Pangloss\%20in\%20Brussels\%20-\%207\%20October\%202016.pdf

EU Commission (2014), "Statement of Commissioner Malmstrom on the entry into force of the Readmission Agreement between Turkey and the EU», en http:// europa.eu/rapid/press-release_STATEMENT-14-285_en.htm

(2015a), "Communication from the Commission to the European Parliament, the Council, the European Economic and Social Committee and the Committee of the Regions. A European Agenda on Migration», en http://ec.europa. eu/dgs/home-affairs/what-we-do/policies/european-agenda-migration/ background-information/docs/communication_on_the_european_agenda_on migration_en.pdf

(2015b), «Managing the refugee crisis: immediate operational, budgetary and legal measures under the European, Agenda on Migration», en http://europa.eu/ rapid/press-release_IP-15-5700_en.htm

(2016a), «Commission recommends extending temporary internal border controls for a limited period of three months», en http://europa.eu/rapid/ press-release_IP-16-3501_en.htm

(2016b), «Delivering on migration and border management: Commission reports on progress made under the European Agenda on Migration", en http:// europa.eu/rapid/press-release_IP-16-3183_en.htm 
(2016c), «Hotspots state of play», en http://ec.europa.eu/dgs/home-affairs/ what-we-do/policies/european-agenda-migration/press-material/docs/state_of play___ hotspots_en.pdf

(2016d), «Managing the refugee crisis. Greece: State of play report», en http:// ec.europa.eu/dgs/home-affairs/what-we-do/policies/european-agendamigration/background-information/docs/greece_state_of_play_report_en.pdf

(2016e), "Member States support to Emergency Relocation Mechanism», en http://ec.europa.eu/dgs/home-affairs/what-we-do/policies/european-agendamigration/press-material/docs/state_of_play___relocation_en.pdf

(2016f), «Proposal for a Dublin regulation recast», en http://europa.eu/rapid/ press-release_IP-16-1620_en.htm

(2016g), "Questions \& Answers: the new European Border ans Coast Guard Agency», en http://europa.eu/rapid/press-release_MEMO-16-3308_en.htm

(2016h), «Recommendation addressed to the Hellenic Republic on the urgent measures to be taken by Greece in view of the resumption of transfers under Regulation (EU) No. 604/2013», en http://eur-lex.europa.eu/legal-content/EN/ TXT/? Uri = CELEX\%3A32016H0193

(2016i), «Relocation and ressetlement: EU Member States must act to sustain current management of flows», en http://europa.eu/rapid/press-release_IP-161763 en.htm

(2016j), «Securing Europe's external borders. A European border and coast guard», en http://ec.europa.eu/dgs/home-affairs/what-we-do/policies/securing-euborders/fact-sheets/docs/20161006/a_european_border_and_coast_guard_en.pdf (2016k), «The European Union and Afghanistan reach an arrangement to tackle migration issues», en http://europa.eu/rapid/press-release_MEX-16-3282 _en.htm

EU Council (2015), "Council Decision (EU) 2015/1601 of 22 September 2015 establishing provisional measures in the area of international protection for the benefit of Italy and Greece», en http://eur-lex.europa.eu/eli/dec/2015/1601/oj

(2015), «Valletta Summit on migration 11-12/11/2015», en http://www. consilium.europa.eu/en/meetings/international-summit/2015/11/11-12/

EU Parliament (2016a), «Internal border controls in the Schengen area: Is Schengen crisis-proof?», en http://www.europarl.europa.eu/RegData/etudes/STUD/2016/ 571356/IPOL _ STU(2016)571356 _ EN.pdf 
(2016b), "On the frontline: the hotspot approach to managing migration», en http://www.europarl.europa.eu/thinktank/en/document.html? reference $=$ IPOL_STU(2016)556942

European Union External Action (2016), «European Union Naval Force-Mediterranean Operation Sophia», en https://eeas.europa.eu/csdp/missions-andoperations/eunavfor-med/pdf/factsheet_eunavfor_med_en.pdf

Eurostat (2016), «Asylum statistics», en http://ec.europa.eu/eurostat/statistics-explained /index.php/Asylum_statistics

Frontex (2014), «Frontex joint operation Triton. Concerned efforts for managing migratory flows in the Central Mediterranean», en http://europa.eu/rapid/ press-release_MEMO-14-609_en.htm

(2016a), «Risk Analysis for 2016 Annual Report», en http://frontex.europa.eu/ assets/Publications/Risk_Analysis/Annula_Risk_Analysis_2016.pdf

(2016b), «Eastern Mediterranean route», en http://frontex.europa.eu/trendsand-routes/eastern-mediterranean-route/

(2016c), «Central Mediterranean route», en http://frontex.europa.eu/trendsand-routes/central-mediterranean-route/

(2016d), «Western Mediterranean route», en http://frontex.europa.eu/trendsand-routes/eastern-borders-route/

(2016e), «Eastern Borders route», en http://frontex.europa.eu/trends-androutes/eastern-borders-route/

(2016f), «Western Balkan route», en http://frontex.europa.eu/trends-androutes/western-balkan-route/

(n.d), «Migratory routes map», en http://frontex.europa.eu/trends-and-routes/ migratory-routes-map/

Gagrielli, Lorenzo (2008), "Flux et contre-flux entre l'Espagne et le Senegal. L'externalisation du contrôle des dynamiques migratoires vers l'Afrique de l'Ouest», en Asylon(s), 3.

Garelli, Glenda \& Tazzioli, Martina (2016), «Warfare on the logistics of migrant movement: EU and NATO military operations in the Mediterranean», en https:// www.opendemocracy.net/mediterranean-journeys-in-hope/glenda-garellimartina-tazzioli/warfare-on-logistics-of-migrant-movem

Heijer, Maarten den \& Thomas Spijkerboer (2016), "Is the EU-Turkey refugee and migration deal a treaty?», EU Law Analysis, en http://eulawanalysis.blogspot. $\mathrm{mx} / 2016 / 04 /$ is-eu-turkey-refugee-and-migration-deal.html 
Heller, Charles \& Pezzani, Lorenzo (2016), «Ebbing and flowing: The EU's Shifting Practices of (non-) assistance and bordering in a time of crisis», en http://nearfuturesonline. org/ebbing-and-flowing-the-eus-shifting-practices-of-non-assistance-andbordering-in-a-time-of-crisis/

IOM (2016a), "Global Migration Trends Factsheet», en http://iomgmdac.org/global -trends-factsheet/

(2016b), «Mixed Migration Flows in the Mediterannean and Beyond, Compilation of available data and information", Reporting period Quarter 2.

Kuschminder, Katie, de Bresser, Juilia \& Siegel, Melissa (2015), Irregular Migration Routes to Europe and Factors Influencing Migrant's Destination Choices, Maastricht Graduate School of Governance (MGSoG).

McAuliffe, Marie (2016), «The appification of migration. A million applicants? There are apps for that», en http://www.policyforum.net/the-appification-of-migration/

MEDMIG Project (2016), «Unpacking a rapidly changing phenomenon: Migration flows, routes and trajectories across the Mediterannean», en https://www. compas.ox.ac.uk/media/PB-2016-MEDMIG-Unpacking_Changing_Scenario.pdf

Ministero della Difesa (2013), «Mare Nostrum operation», en http://www.marina. difesa.it/EN/operations/Pagine/MareNostrum.aspx

Oxfam (2016), «Hotspot, rights denied. The lack of a legal framework is threatening the rights of migrants reaching the Italian shore», en http://reliefweb.int/sites/ reliefweb.int/files/resources/bp-hotspots-migrants-italy-220616-en.pdf

Rasmussen, Sune Engel (2016), «EU signs deal to deport to unlimited numbers of Afghan asylum seekers», The Guardian, en https://www.theguardian.com/global-development /2016/oct/03/eu-european-union-signs-deal-deport-unlimited -numbers-afghan-asylum -seekers-afghanistan

Tardy, Thierry (2015), "Operation Sophia: tackling the refugee crisis with military means», Institute for Security Studios, 30(30), en http://www.iss.europa.eu/ publications/detail/article/operation-sophia-tackling-the-refugee-crisis-withmilitary-means

Tazzioli, Martina (2015), «The Desultory Politics Of Mobility And The Humanitarian-Military Border In The Mediterranean. Mare Nostrum Beyond The Sea». REMHU: Revista Interdisciplinar Da Mobilidade Humana, 44(23).

Triandafyllidou, Anna (2017), "A srefugee crisis unfolding: Real events and their interpretation in media and political debates», Journal of Immigrant and Refugee Studies, forthcoming. 
Triandafyllidou, Anna \& Gropas, Ruby (2014), "Greece», en Triandafyllidou y Gropas (eds.), European immigration, a sourcebook Ashgate.

Triandafyllidou, Anna, Gropas, Ruby \& Vogel, Dita (2014), "Introduction», en Triandafyllidou y Gropas (eds.), European immigration, a sourcebook Ashgate.

Triandafyllidou, Anna \& Maroukis, Thanos (2012), Migrant smuggling. Irregular migration from Asia and Africa to Europe, Palgrave Macmillan, London.

(2010), Migration in 21st century Greece, Kritiki, Athens.

UNHCR (2016a), «Refugees Migrants Emergency response-Mediterranean», en http:// data.unhcr.org/mediterranean/country.php?id=83

(2016b), «Weekly accommodation and relocation update», en http://reliefweb. int/sites/reliefweb.int/files/resources/Accommodation-Relocationupdateasof24 October2016.pdf 